\title{
PENGARUH LATIHAN BARRIER HOPS TERHADAP KETEPATAN JUMP SERVICE PADA CABANG OLAHRAGA BOLA VOLI MAHASISWA UKM UNIPA
}

\author{
Riga Mardhika ${ }^{1}$ Yandika Fefrian Rosmi ${ }^{2}$ \\ Prodi Pendidikan Jasmani, FKIP, Universitas PGRI Adi Buana Surabaya \\ riga@unipasby.ac.id ${ }^{1}$ yandika@unipasby.ac.id ${ }^{2}$
}

\begin{abstract}
ABSTRAK
Penelitian ini bertujuan untuk mengetahui pengaruh latihan barrier hops terhadap ketepatan jump service pada permainan bola voli. Populasi penelitian ini adalah seluruh mahasiswa putra peserta UKM bola voli Unipa Surabaya berjumlah 20 mahasiswa, teknik sampling yang digunakan dalam penelitian ini menggunakan total sample. Metode dalam penelitian ini menggunakan metode eksperimen dengan desain one grup pre-test dan post-test design. Pengambilan data dalam penelitian ini menggunakan test dan pengukuran. Teknik analisis data dalam penelitian ini menggunakan analis uji t. Hasil pengujian hipotesis menunjukkan bahwa nilai probabilitas signifikan sebesar 0,000 $<0,05$ atau thitung $>\mathrm{t}$ tabel (53.461>17291) yang berarti bahwa latihan barrier hops berpengaruh secara signifikan terhadap ketepatan jump service pada permainan bola voli.
\end{abstract}

Kata Kunci: Ketepatan Jump Service, Pelatihan Barrier Hops, Bolavoli.

\section{PENDAHULUAN}

Olahraga adalah sesuatu yang wajib dilakukan seseorang guna memperoleh kesehatan jasmani dan rohani. Banyaksarana dan prasarana yang bisa dilakukan dimanapun guna mendapatkan tubuh yang sehat dan bugar. Pada jaman yang seperti ini masyarakat lebih memilih olahraga yang murah ketimbang harus pergi ke tempat fitnes yang jaraknya lumayan jauh dari rumah atau membeli alat olahraga yang harganya jauh lebih mahal. Di antaranya olahraga yang sering dilakukan oleh masyarakat adalah bermain bola voli, di mana olahraga bola voli merupakan olahraga yang bisa dilakukan secara berkelompok di kalangan masyarakat.

Olahraga bola voli merupakan cabang olahraga yang di sukai di masyarakat karena minim kontak secara fisik, sehingga kemungkinan cedera relatif sangat kecil, mudah dimainkan yaitu hanya dengan cara memantul-mantulkan bola kepada lawan, sedangkan peraturan dalam permainanya tergolong mudah dan permainan tersebut enak dinikmati oleh penonton. Pertandingan bola voli selalu masuk dalam kalender multi even, seperti PON, POPNAS dan lain sebagainya. (Ali Maksum, 2011) 
Permainan bola voli dapat dimainakan di mana saja baik di dalam ruangan maupun diluar ruangan. Jumlah standar pemaian dalam bola voli tidak terbatas. Inti dari permainan ini adalah mempertahankan bola agar tetap bergerak melewati net, dari wilayah satu ke wilayah yang lainnya.

Olahraga bola voli banyak digemari oleh anak muda jaman sekarang mulai dari anak sekolah dasar sampai pada mahasiswa perguruan tinggi. Semakin banyak peminatnya, maka makin banyak pula kejuaran bola voli yang diadakan oleh suatu instansi baik itu pemerintahan maupun swasta. Melihat persaingan yang terjadi pada saat kejuaraan bola voli guna mendapatkan prestasi, maka pentingnya penguasaan teknik dasar bola voli serta kebugaran jasmani yang harus dimiliki oleh setiap pemain bola voli. Diantaranya penguasaan teknik dasar yang meliputi smash, pasing, service dan blok, serta komponen kebugaran jasmani yang meliputi kekuatan, kelincahan, keseimbangan, kecepatan, ketahanan dan koordinasi (Sukadianto, 2011:57).

Di dalam kejuaraan sering kali terjadi kesalahan yang dilakukan oleh pemain bola voli yaitu kegagalan dalam melakukan Jump Service. Dimana seorang pemain tidak mampu melakukan lompatan dengan baik sehingga pada saat melakukan jump service pukulan tidak sesuai sasaran atau bola tidak bisa melewati net. Metode pelatihan barrier hops merupakan metode yang tepat dalam upaya meningkatkan kapasitas fisik para pemain bola voli khususnya meningkatkan vertical jump. Metode latihan ini mengutamakan kekuatan otot tungkai yang memiliki pengaruh terhadap lompatan. Sasaran utama dalam latihan ini adalah pada tinggi lompatan. Atas dasar dari beberapa teori yang ada, maka perlu adanya penelitian yang bisa mengkaji Pengaruh Pelatihan Barrier Hops Terhadap Ketepatan Jump Service pada Permainan Bola Voli.

Mengingat pentingnya prestasi bola voli yang baik, maka para pemain perlu dilatih secara khusus dan terus menerus untuk meningkatkan ketepatan maksimal. Banyak cara dan metode yang digunakan. Sehubungan dengan ketepatan Jump Service, maka peneliti ingin mengetahui Pengaruh Pelatihan Barrier Hops Terhadap Ketepatan Jump Service Pada Cabang Olahraga Bola Voli Mahasiswa UKM Unipa.

Berdasarkan penjelasan diatas penelitian ini difokuskan terhadap Pengaruh Pelatihan Barrier Hops Terhadap Ketepatan Jump Service Pada Cabang Olahraga Bola Voli Mahasiswa UKM Unipa. Agar penelitian ini tidak melebar kemana-mana dan mempunyai batasan masalah, maka penelitian ini memusat padaPelatihan 
Barrier Hops dengan Ketepatan Jump Service Cabang Olahraga Bola Voli Mahasiswa UKM Unipa.

\section{METODE PENELITIAN}

Metode penelitian ini menggunakan metode eksperimen dengan pendekatan kuantitatif. Penelitian ekperimen adalah penelitian yang dilakukan mengetahui hubungan sebab akibat di antara variable (Ali Maksum. 2012:64).

Sesuai dengan permasalahan peneltian, dalam penelitian ini menggunakan desain one group pretestposttest design yang di dalam pelaksanaannya sampel yang digunakan diberlakukan pretest kemudian diberikan perlakuan lalu hasil akhir dilakukan posttest.

Di dalam suatu penelitian menentukan populasi dan sampel itu merupakan hal yang penting. Dalam penelitian ini populasinya adalah seluruh mahasiswa peserta UKM Bolavoli berjumlah 20 peserta. Penelitian ini menggunakan teknik sampling total sample, sehingga seluruh populasi berjumalah 20 mahasiswa dijadikan sebagai sampel.

Menurut Sukardi (2003:121) suatu instrumen dikatakan valid jika instrumen yang digunakan dapat mengukur apa yang hendak diukur, maka peneliti akan mengukur ketepatan jump service menggunakan tes ketepatan.
1. Cara pelatihan barrier hops:

Pertama berdiri dibelakang gawang lompatan, kemudian berdiri dengan kaki dibuka selebar bahu. Setelah itu membungkukkan badan hanya sampai pinggul, kemudian tolakkan lutut ke atas untuk melompati gawang lompatan. Jangan biarkan lutut belok ke samping atau membuka terkena gawang lompatan (Chu, 2013:123). Tujuan melakukan tes ketepatan jump service adalah untuk mengukur ketepatan mengarahkan bola dengan cepat dalam service (Albertus, Muhyi, 2015:200).

Data yang diperoleh pada penelitian ini selanjutnya diolah atau dianalisis dengan menggunakan perhitungan statistik. Menurut Sugiyono (2011:243) analisis data merupakan kegiatan pengelompokan data berdasarkan;(1) variabel dan jenis responden, (2) mentabulasikan data berdasarkan variabel dari seluruh responden, (3) menyajikan data setiap variabel yang diteliti, (4) melakukan perhitungan untuk menjawab rumusan masalah dan (5) melakukan perhitungan untuk menguji hipotesis yang telah diajukan dengan T-Test sampel sejenis untuk menganalisis hasil data tersebut sebagai berikut.

$$
t=\frac{\sum D}{\sqrt{\frac{\mathrm{N} \sum D^{2}-\left(\sum D\right)^{2}}{\mathrm{~N}-1}}}
$$

(Ali Maksum, 2009:74) 
Keterangan:

$\mathrm{D}=$ perbedaan setiap pasangan skor (pretest-posttest)

$\mathrm{N}=$ jumlah sampel

Kemudian hasil tes diolah menjadi data statistik untuk mengetahui dengan pasti dan objektif apa perubahan dari tes tersebut, sehingga dapat diketahui dengan pasti perbedaan hasil akibat dari perlakuan yang diberikan.

\section{HASIL DAN PEMBAHASAN}

Sebelum diberi perlakuan (treatment) hasil dari pretest ketetapan Jump Service yang dilakukan oleh atlet tersebut sangat rendah, hamper setiap atlet memperoleh angka 1, di mana angka 1 tersebut menunjukkan bahwa atlet tersebut tidak mampu melakukan Jump Service dengan baik. Angka tertinggi pada saat pretest ketetapan Jump Service adalah 8 dan terkecil adalah 1. Sebelum diberi perlakuan (treatment) hasil dari pretest ketetapan Jump Service yang dilakukan oleh atlet tersebut sangat rendah, hampir setiap atlet memperoleh angka 1, di mana angka 1 tersebut menunjukkan bahwa atlet tersebut tidak mampu melakukan Jump Service dengan baik. Setelah diberi perlakuan (treatment) hanya beberapa atlet yang memperoleh angka 1 . Hampir keseluruhan atlet memperoleh nilai terbaik yaitu 15 dan ada beberapa atlet memperoleh nilai 12 .
Setelah diketahui nilai tersebut di atas, maka data tersebut di analisis secara statistik menggunakan uji $t$ dengan langkah-langkah sebagai berikut.

Uji $\mathrm{t}=\frac{\sum D}{\sqrt{\frac{\mathrm{N \Sigma} D^{2}-(\Sigma D)^{2}}{\mathrm{~N}-1}}}$

(Ali Maksum, 2009:74)

Keterangan :

$\mathrm{D}=$ perbedaan setiap pasangan skor (pretest-posttest)

$\mathrm{N}=$ jumlah sampel

Penghitungan Uji t:

$$
\begin{aligned}
& t=\frac{\sum D}{\sqrt{\frac{N \sum D^{2}-\left(\sum D\right)^{2}}{\mathrm{~N}-1}}} \\
& t=\frac{417}{\sqrt{\frac{20.8753-(417)^{2}}{20-1}}} \\
& t=\frac{417}{\sqrt{\frac{175060-173889}{19}}} \\
& t=\frac{417}{\sqrt{\frac{1171}{19}}} \\
& t=\frac{417}{\sqrt{61.63}}=\frac{417}{7.8}=53.461 \\
& t_{\text {hitung }}=53.461 \\
& \text { derajat kebebasan }=\mathrm{N}-1 \\
& \quad=20-1=19 \\
& t_{\text {tabel }} 5 \% \text { dari satu sisi }=1.729
\end{aligned}
$$

Hasil pengujian hipotesis menunjukkan bahwa nilai probabilitas signifikan sebesar $0,000<0,05$ atau $\mathrm{t}$ hitung $>\mathrm{t}$ tabel $(53,461>17291)$ yang berarti bahwa Pelatihan Barrier Hops 
berpengaruh secara signifikan terhadap ketepatan Jump Service pada permainan bola voli.

Hipotesis menyatakan ada Pengaruh Barrier Hops terhadap ketepatan Jump Service dalam Permainan Bola Voli UKM Putra Universitas PGRI Adi Buana Surabaya diterima.

Maka, karena hasilnya positif, intensitas latihan menggunakan tes Barrier Hops perlu adanya peningkatan. Sehingga hasil pada ketepatan Barrier Hops memiliki hasil yang cukup maksimal dalam melakukan Jump Service. Selain mengunakan latihan Barrier Hops, latihan perlu adanya pemrograman yang dilakukan secara kontekstual sehingga memiliki kemampuan melakukan ketepatan Jump service yang maksimal yang memiliki dampak keberhasilan mencetak poin dalam permainan bola voli.

\section{SIMPULAN}

Dari data di atas bisa disimpulkan bahwa:

1. Ada Pengaruh Pelatihan Barrier Hops Ketepatan Jump Service pada permainan Bola Voli UKM Putra Unipa.

2. Ada pengaruh barrier hops terhadap ketepatan jump service pada saat melakukan jump service dalam permainan bola voli.
3. Latihan barrier hops memiliki pengaruh yang signifikan terhadap ketepatan dalam melakukan jump service.

4. Latihan koordinasi barrier hops mampu menghasilkan ketepatan jump service yang maksimal dalam permainan bola voli.

Penelitian ini merupakan informasi yang empiris yang dapat dijadikan sebagai bahan pertimbangan dalam pemilihan atlet yang berbakat untuk dijadikan atlet yang berprestasi, khususnya pada cabang olahraga bola voli. Berdasdasarkan hasil penelitian ini, maka penulis mengajukan saransaran sebagai berikut:

a. Bagi pembina atau pelatih cabang olahraga bola voli, selalu mencari informasi yang objektif mengenal faktor-faktor yang dapat meningkatkan prestasi bola voli.

b. Untuk meningkatkan prestasi bola voli, maka ditingkatkan pula kondisi fisik dengan memberikan latihanlatihan yang efektif.

c. Penelitian ini bisa digunakan sebagai pegangan dalam pelatihan fisik olahraga bola voli khususnya dalam meningkatkan jump srvice dalam permainan bola voli.

d. Pelatihan barrier hops bisa dimasukkan dalam program latihan peningkatan ketepatan dalam olahraga bola voli. 


\section{DAFTAR PUSTAKA}

Arikunto, S. 2002. Metodologi Pendidikan

Suatu Pendekatan Proposal. Jakarta: PT Rineka Cipta.

Bompa, Tudor. (1994) Theory and Methodology of Training. Kendal. Lowa: Hunt Publishing Company

Chu, PhD. 2013. Plyometrics. United Stade Of America: Sheridan Books.

Maksum Ali. 2009. Tes Dan Pengkuran Pendidikan Olahraga. Fakultas Pendidikan Olahraga Dan Kesehatan. Universitas Pendidikan Surabaya.

Maksum Ali.2011.Buku Ajar bola voli edisi pertama. Surabaya: Unesa University Press-2011.

Muhajir. 2007. Pendidikan Jasmani Olahraga Dan Kesehatan Untuk SMA Kelas X. Ciracas Jakarta. Erlangga.

Muhyi, Fenan lampir.2015. Tes $\mathcal{E}$ Pengukuran dalam Olahraga. Yogyakarta: CV. Andi Offset.

Muhyi, Mutohir, dkk. 2013. Permainan bola voli konsep teknik strategi $\mathcal{E}$ modifikasi. Surabaya: Graha Pustaka Media Utama.

Sugiyono. 2010. Metode Penelitian Pendekatan Kuantitatif, kualitatif, dan RED. Bandung: Alfabeta.

Sukadianto.2011. Pengantar Teori Metedologi. Bandung: Lubuk Agung.
Persatuan Bola Voli Seluruh Indonesia.2001. Peraturan Bola Voli. Jakarta: PB PBVSI.

Pranatahadi (2009). Smes dalam Bola Voli Yogyakarta: FIK UNY.

Sukardi. 2003. Metodologi Penelitian Pendidikan Kompetensi dan Praktiknya. Jakarta: Bumi Aksara. 